\title{
Atenção odontológica à pacientes portadores de hanseníase: uma revisão integrativa
}

\author{
Dentistry attention to patients with hanseniasis: an integrating review
}

Atención odontológica a pacientes portadores de hanseniasis: una revisión integrativa

\begin{abstract}
Amujacy Tavares Vilhena ${ }^{1 *}$, Aluísio Ferreira Celestino Júnior ${ }^{1}$, Lucianna Patrícia de Souza Miranda Mendes ${ }^{1}$, Aurino Ortega Fernandes Vulcão ${ }^{1}$, Wanda do Nascimento Meireles Vilhena ${ }^{2}$.
\end{abstract}

\section{RESUMO}

Objetivo: Identificar as principais produções científicas da odontologia aplicada a hanseníase e analisar descritivamente os resultados das pesquisas produzidas para a construção do conhecimento na área. Métodos: Revisão integrativa da literatura sobre a temática em artigos publicados no período de 1980 a 2018. Utilizou-se como estratégia de identificação e seleção dos artigos o levantamento de estudos indexados nos bancos de dados disponíveis na Biblioteca Virtual de Saúde - BVS: Lilacs, Medline; SciELO e Pubmed. Resultados: Foram identificados 136 artigos. Seguindo os critérios de elegibilidade, foram excluídos 121 artigos, pois não estavam em concordância com os parâmetros previamente estabelecidos e por apresentarem-se repetidos nos diferentes bancos de dados. Dessa forma, a amostra final foi composta por 15 artigos científicos produzidos pela odontologia ou com sua participação, publicados em língua inglesa, espanhola, portuguesa e francesa. Conclusão: De acordo com as publicações analisadas nesta revisão, há poucos artigos produzidos sobre os protocolos adequados do atendimento odontológico à pacientes com hanseníase. Assim, mesmo de forma tímida, as pesquisas contribuem ao desenvolvimento do conhecimento, atendimento integral e humanizado aos pacientes que são ou foram portadores de Hanseníase.

Palavra-chave: Odontologia, Saúde Bucal, Hanseníase.

\section{ABSTRACT}

Objective: to identify the main scientific productions of dentistry applied to leprosy and to analyze descriptively the results of researches produced for the construction of knowledge in the area. Methods: An integrative review of the literature on the subject was developed in articles published in the period from 1980 to 2018. It was used as a strategy of identification and selection of articles the survey of studies indexed in the databases available in the Virtual Health Library - VHL: Lilacs, Medline; SciELO and Pubmed. Results: 136 articles were identified. Following the eligibility criteria, 121 articles were excluded because they were not in agreement with the previously established parameters and because they were repeated in the different databases. Thus, the final sample consisted of 14 scientific articles produced by dentistry or with their participation published in English, Spanish, Portuguese and French. Conclusion: According to the publications analyzed in this review, there are few articles produced on the adequate protocols of dental care for patients with leprosy. Thus, even in a timid manner, research contributes to the development of knowledge, comprehensive and humanized care for patients who are or were carriers of leprosy.

Key words: Dentistry, Oral Health, Leprosy.

\section{RESUMEN}

Objetivo: identificar las principales producciones científicas de la odontología aplicada a la lepra y analizar descriptivamente los resultados de las invstigaciones producidas para la construcción del conocimiento en el área. Métodos: Revisión integrativa de la literatura sobre la temática en articulos publicados en el período de 1980 a 2018 . Se utilizó como estrategia de identificación y selección de los artículos el levantamiento de estudios indexados en los bancos de datos disponibles en la Biblioteca Virtual de Salud - BVS: Lilacs, Medline; SciELO y Pubmed. Resultados: Se identificaron 136 artículos. Siguiendo los criterios de elegibilidad, fueron excluidos 121 artículos, pues no estaban en

${ }^{1}$ Centro Universitário do Estado do Pará, Belém do Pará. * E-mail: amujacy@hotmail.com

${ }^{2}$ Docente da Centro de Educação Profissional DNA, Ananindeua, Pará. 
concordancia con los parámetros previamente establecidos y por presentarse repetidos en las diferentes bases de datos. Por lo tanto, la amuestra final consistió en 15 artículos científicos producidos por la odontologia o con su participación, publicado en Inglés, español, portugués y francés. Conclusión: De acuerdo con las publicaciones analizadas en esta revisión, hay pocos artículos producidos sobre los protocolos adecuados de la atención odontológica a los pacientes con lepra. Asi, incluso de forma tímida, las investigaciones contribuye al desarrollo del conocimiento, atención integral y humanizada a los pacientes que son o fueron portadores de Hanseniasis.

Palabra-clave: Odontología, Salud Bucal, Hanseniasis.

\section{INTRODUÇÃO}

A hanseníase é uma doença crônica infecciosa granulomatosa causada por um bacilo álcool-ácido resistente, Mycobacterium leprae, de evolução lenta que apresenta um tropismo peculiar para pele, nervos periféricos e mucosas, em especial ao trato respiratório, podendo afetar outros órgãos como o fígado, os testículos, os olhos e a cavidade bucal. Acredita-se que lesões na mucosa oral são fonte de infecção em pacientes multibacilar, que possui como característica uma alta contagem de bacilos viáveis e os mesmos podem expelir grande número de bacilos ao espirrar, cuspir, tossir ou falar, sendo uma via aberta de contaminação (FUCCI DA COSTA et. al., 2003).

O mecanismo de transmissão da hanseníase não está claro, porém acredita-se que aconteça pelo contato íntimo e prolongado com o doente através das secreções nasais e orofaríngeas e/ou pelas lesões cutâneas (PONTES et al., 2008).

O Mycobacterium leprae apesar de potencialmente infeccioso, tem baixa patogenicidade e virulência (OSUGUE, 2005).

Baseando-se na predileção do bacilo de Hansen pelos nervos periféricos, na hipótese da cavidade oral ser rota de entrada e saída do bacilo no organismo, e pelo resultado de estudos utilizando a PCR que confirmaram a presença do bacilo na cavidade oral (SANTOS et al., 2007), percebe-se a necessidade de avaliar a sensibilidade intra-oral dos sujeitos com hanseníase para identificar a presença ou não de comprometimento dos nervos periféricos.

A hanseníase ainda representa um grave problema de saúde pública, considerada uma doença de notificação compulsória, apesar de existir o desenvolvimento de diversas pesquisas nos últimos anos. Constata-se que houve uma diminuição da prevalência da doença nos últimos 20 anos, isto se deve a contribuição das ações de descentralização das campanhas de controle e, em grande parte, pela introdução da poliquimioterapia (PQT). Porém, no Brasil e em diversos outros países essa queda substancial não ocasionou alterações quanto aos aspectos de transmissibilidade (OMS, 2014).

No Brasil, o Ministério da Saúde se comprometeu em erradicar a hanseníase como problema de saúde pública até 2015, isto significa que deveria existir uma taxa menor que um caso por 10.000 habitantes. Entretanto, em 2012 o valor do coeficiente foi de 1,51/10.000 habitantes. As regiões Norte, Nordeste e Centro-Oeste, totalizam $53,5 \%$ dos casos novos detectados em apenas $17,5 \%$ da população brasileira. Estes dados revelam o cenário preocupante de uma doença que parecia estar sendo controlada (BRASIL, 2013).

No contexto da Hanseníase, o cirurgião dentista atua em ações de promoção e prevenção de saúde bucal tendo como competência prestar assistência odontológica realizando a avaliação diagnóstica, tratamento, reabilitação e prevenção. Além dessas competências, ele desenvolve ações educativas, ações integradas com outros profissionais, apoia a pesquisa em odontologia o que é essencial para gerar a base de conhecimento que fundamenta a prática clínica, além de poder identificar o impacto da hanseníase e do tratamento na vida destes pacientes.

Essas considerações justificam a relevância em desenvolver uma revisão integrativa sobre a produção científica em atendimento odontológico tanto no âmbito nacional quanto internacional, pois só assim 
conheceremos o que está sendo produzido na área odontológica com o propósito de auxiliar o desenvolvimento de futuras pesquisas.

Sendo assim, estipulamos como questão norteadora desta revisão: os artigos publicados pelos autores estão contribuindo para o desenvolvimento do conhecimento e atendimento adequado dos pacientes portadores de Hanseníase.

O objetivo principal desta revisão é apresentar a contribuição das pesquisas produzidas no campo da odontologia voltado a pacientes com Hanseníase. Escolhemos como objetivos específicos realizar o levantamento das produções científicas desenvolvidas pela odontologia com o tema supracitado nas bases de dados nacionais e internacionais; identificar os autores, os tipos de pesquisa, a coerência teóricometodológica dos artigos e os resultados.

\section{MÉTODOS}

A metodologia utilizada neste trabalho para se chegar ao objetivo geral, foi uma revisão integrativa, com o intuito de encontrar as pesquisas desenvolvidas pela odontologia que trazem contribuições mais relevantes e atuais ao tema abordado.

Utilizou-se como estratégia de identificação e seleção dos artigos o levantamento de estudos indexados nos bancos de dados disponíveis na Biblioteca Virtual de Saúde (BVS), nas bases de dados Literatura Latino-americana e do Caribe de Informação em Ciências de Saúde (Lilacs), Medical Literature Analysis and Retrieval System Online (Medline), Scientific Electronic Library Online (SciELO) e PUBMED.

Os termos utilizados na seleção foram delimitados, a partir das palavras-chave presentes em artigos adequados ao tema, lidos previamente de forma não sistemática e por meio de consulta às coleções de termos cadastrados nos Descritores em Ciências da Saúde (DeCS). Foram utilizados os seguintes descritores: "odontologia", "hanseníase" e "saúde bucal". Realizamos o agrupamento dos descritores da seguinte forma: "odontologia e hanseníase", "saúde bucal e hanseníase". Os critérios de inclusão utilizados para a seleção da amostra foram: artigos publicados em periódicos em língua inglesa, espanhola, portuguesa e francesa; artigos que respondessem a questão norteadora, artigos que abordassem a temática do atendimento ao paciente portador de hanseníase referente as áreas de interesse da odontologia; periódicos indexados nos bancos de dados BVS, SciELO e PUBMED e artigos publicados de 1980 até o ano de 2018. Como critério de exclusão demais estudos como dissertações, teses e manuais de saúde.

Foram identificados 136 artigos. No entanto, após serem adquiridas todas as cópias e realizada a leitura dos artigos, optou-se por excluir 108, pois não estavam em concordância com os critérios estabelecidos e por apresentarem-se repetidos nos diferentes bancos de dados, permanecendo assim 28 estudos.

Posteriormente, foi realizada uma pré-seleção mediante a leitura de títulos e resumos colocando-os em uma planilha de análises a fim de selecionar as pesquisas que respondessem à questão norteadora.

Dessa forma, a amostra final foi composta por 15 artigos científicos produzidos pela odontologia ou com sua participação, publicados em língua inglesa, espanhola, portuguesa e francesa. Os artigos encontrados foram numerados conforme a ordem de localização, e os dados foram analisados segundo os seus conteúdos pela estatística descritiva.

\section{RESULTADOS E DISCUSSÃO}

A pesquisa da revisão integrativa ocorreu em três bases de dados, sendo essas: SciELO, Pubmed e Biblioteca Virtual de Saúde. Após a busca nas bases de dados e estabelecidos artigos selecionados, chegou-se ao total de 15 estudos. Sendo encontrados 10 artigos na BVS, 3 na SciELO e 2 no Pubmed (Quadro 01). 
Quadro 01 - Distribuição dos estudos analisados quanto ao autor/ano, periódico, título e objetivo.

\begin{tabular}{|c|c|c|c|c|}
\hline $\mathbf{N}$ & Autor/ ano & Periódico & Título & Objetivo \\
\hline 01 & $\begin{array}{l}\text { Martins et al. } \\
2016\end{array}$ & $\begin{array}{l}\text { Revista do } \\
\text { Instituto de } \\
\text { Medicina Tropical } \\
\text { do estado de São } \\
\text { Paulo }\end{array}$ & $\begin{array}{l}\text { Dentists' knowledge } \\
\text { and experience } \\
\text { regarding leprosy in } \\
\text { an endemic area in } \\
\text { Brazil }\end{array}$ & $\begin{array}{l}\text { Analisar o conhecimento dos cirurgiões-dentistas } \\
\text { sobre a hanseníase, suas formas de transmissão, } \\
\text { características clínicas, tratamento e cuidados } \\
\text { prestados aos pacientes, bem como suas } \\
\text { experiências com suspeita diagnóstica e } \\
\text { encaminhamento. }\end{array}$ \\
\hline 02 & $\begin{array}{l}\text { Dave et al. } \\
2013\end{array}$ & $\begin{array}{l}\text { International } \\
\text { Dental Journal }\end{array}$ & $\begin{array}{l}\text { Leprosy and its dental } \\
\text { management } \\
\text { guidelines }\end{array}$ & $\begin{array}{l}\text { Avaliar as manifestações orofaciais da doença em } \\
\text { pacientes atendidos nas clínicas do Projeto de } \\
\text { Hanseníase em Bombaim e desenvolver diretrizes } \\
\text { clínicas para dentistas. }\end{array}$ \\
\hline 03 & $\begin{array}{l}\text { Almeida et } \\
\text { al. } \\
2011\end{array}$ & $\begin{array}{l}\text { Cadernos Saúde } \\
\text { Coletiva }\end{array}$ & $\begin{array}{l}\text { Contribuição do } \\
\text { cirurgião-dentista no } \\
\text { controle da } \\
\text { hanseníase }\end{array}$ & $\begin{array}{l}\text { Avaliar o conhecimento, atitudes e práticas do } \\
\text { cirurgião-dentista (CD) no controle da hanseníase } \\
\text { na Secretaria Executiva Regional III (SER III), } \\
\text { município de Fortaleza (CE), Brasil, sensibilizando } \\
\text { para o diagnóstico precoce de infecções da boca, } \\
\text { que são importantes eventos predisponentes de } \\
\text { complicações e estados reacionais. }\end{array}$ \\
\hline 04 & $\begin{array}{l}\text { Cortela et al. } \\
\qquad 2008\end{array}$ & $\begin{array}{l}\text { Revista Brasileira } \\
\text { de Epidemiologia }\end{array}$ & $\begin{array}{l}\text { Lesões visíveis na } \\
\text { hanseníase: o papel } \\
\text { do cirurgião-dentista } \\
\text { na suspeita de casos } \\
\text { novos }\end{array}$ & $\begin{array}{l}\text { Analisar as principais características } \\
\text { epidemiológicas dos portadores de hanseníase } \\
\text { com ênfase na área de localização das lesões. }\end{array}$ \\
\hline 05 & $\begin{array}{l}\text { Cortela et al. } \\
2008\end{array}$ & $\begin{array}{l}\text { Revista. Odonto } \\
\text { ciências }\end{array}$ & $\begin{array}{l}\text { Conhecimento e } \\
\text { experiências do } \\
\text { cirurgião-dentista } \\
\text { sobre hanseníase em } \\
\text { Cáceres, MT, Brasil }\end{array}$ & $\begin{array}{l}\text { Analisar o conhecimento e as experiências dos } \\
\text { CDs relativos à suspeita diagnóstica e ao } \\
\text { encaminhamento de casos de hanseníase. }\end{array}$ \\
\hline 06 & $\begin{array}{l}\text { Núñez Martí, } \\
\text { Juan Manuel } \\
2000\end{array}$ & $\begin{array}{l}\text { Revista de } \\
\text { leprologia } \\
\text { Fontilles }\end{array}$ & $\begin{array}{l}\text { Calidad odontológica } \\
\text { en pacientes con } \\
\text { Hansen }\end{array}$ & $\begin{array}{l}\text { Identificar o plano de ação relacionados a } \\
\text { cuidados preventivos e terapêuticos de atenção à } \\
\text { saúde bucal relacionando-os a qualidade de vida } \\
\text { de portadores de hanseníase." }\end{array}$ \\
\hline 07 & $\begin{array}{l}\text { Almeida et } \\
\text { al. } \\
2017\end{array}$ & $\begin{array}{l}\text { Revista do } \\
\text { Instituto de } \\
\text { Medicina Tropical } \\
\text { do estado de São } \\
\text { Paulo }\end{array}$ & $\begin{array}{l}\text { Oral health conditions } \\
\text { in leprosy cases in } \\
\text { hyperendemic area of } \\
\text { the Brazilian Amazon }\end{array}$ & $\begin{array}{l}\text { Analisar o perfil clínico-odontológico, a } \\
\text { autopercepção do acesso aos serviços de saúde } \\
\text { bucal e saúde bucal dos casos de hanseníase no } \\
\text { município de Cacoal, Rondônia, no período de } \\
2001 \text { a } 2012 \text {. }\end{array}$ \\
\hline 08 & $\begin{array}{l}\text { Filgueiras et } \\
\text { al. } \\
2014\end{array}$ & $\begin{array}{l}\text { Epidemiologia e } \\
\text { Serviços de } \\
\text { Saúde }\end{array}$ & $\begin{array}{l}\text { Saúde bucal em } \\
\text { indivíduos com } \\
\text { hanseníase no } \\
\text { município de Sobral, } \\
\text { Ceará* / Oral health } \\
\text { in leprosy patients, } \\
\text { Sobral, Ceará state, } \\
\text { Brazil }\end{array}$ & $\begin{array}{l}\text { Avaliar a condição de saúde bucal de pacientes } \\
\text { com hanseníase no município de Sobral, estado } \\
\text { do Ceará, Brasil. }\end{array}$ \\
\hline 09 & $\begin{array}{l}\text { Feng et al. } \\
2014\end{array}$ & Leprosy Review & $\begin{array}{l}\text { Dental health and } \\
\text { treatment needs in } \\
\text { people with leprosy in } \\
\text { China }\end{array}$ & $\begin{array}{l}\text { Avaliar o estado de saúde bucal e as } \\
\text { necessidades de tratamento das pessoas } \\
\text { afetadas pela hanseníase na China e fornecer } \\
\text { uma base para o desenvolvimento de programas } \\
\text { nacionais ou regionais de saúde bucal para cobrir } \\
\text { as necessidades de tratamento dessa população. }\end{array}$ \\
\hline 10 & $\begin{array}{l}\text { Almeida et } \\
\text { al. } \\
2011\end{array}$ & $\begin{array}{c}\text { Ciências \& } \\
\text { Saúde Coletiva }\end{array}$ & $\begin{array}{l}\text { Autopercepção de } \\
\text { pessoas acometidas } \\
\text { pela hanseníase } \\
\text { sobre sua saúde } \\
\text { bucal e necessidade } \\
\text { de tratamento. }\end{array}$ & $\begin{array}{l}\text { Avaliar a autopercepção sobre a saúde bucal e a } \\
\text { necessidade de tratamento em pacientes com } \\
\text { hanseníase na cidade de Fortaleza, Estado do } \\
\text { Ceará, Brasil }\end{array}$ \\
\hline 11 & $\begin{array}{c}\text { Russo et al. } \\
2005 \\
\end{array}$ & $\begin{array}{c}\text { Revista Odonto } \\
\text { ciências }\end{array}$ & $\begin{array}{l}\text { Aspectos da doença } \\
\text { de Hansen relevantes } \\
\text { para o cirurgião- }\end{array}$ & $\begin{array}{l}\text { Realizar uma revisão bibliográfica visando } \\
\text { informar o cirurgião-dentista sobre a situação } \\
\text { atual da DH no Brasil, suas manifestações bucais, }\end{array}$ \\
\hline
\end{tabular}




\begin{tabular}{|c|c|c|c|c|}
\hline & & & $\begin{array}{l}\text { dentista: revisão da } \\
\text { literatura }\end{array}$ & $\begin{array}{l}\text { sequelas que repercutem na saúde bucal e dar } \\
\text { subsídios para que o profissional participe do } \\
\text { diagnóstico desta doença }\end{array}$ \\
\hline 12 & $\begin{array}{l}\text { Santos et al. } \\
\qquad 2000\end{array}$ & $\begin{array}{l}\text { Pesquisa } \\
\text { Odontológica } \\
\text { Brasileira }\end{array}$ & $\begin{array}{l}\text { Aspectos } \\
\text { estomatológicos das } \\
\text { lesões específicas e } \\
\text { näo-específicas em } \\
\text { pacientes portadores } \\
\text { da moléstia de } \\
\text { Hansen / Oral } \\
\text { aspects of specific } \\
\text { and unspecific lesions } \\
\text { in Hansen's disease } \\
\text { patients }\end{array}$ & $\begin{array}{l}\text { Examinar a mucosa bucal de doentes } \\
\text { hansenianos com o objetivo de detectar possíveis } \\
\text { alterações específicas e näo-específicas }\end{array}$ \\
\hline 13 & $\begin{array}{l}\text { Diallo et al. } \\
1992\end{array}$ & Acta leprologica & $\begin{array}{l}\text { Evaluation de l'état } \\
\text { orofacial et dentaire } \\
\text { d'une population } \\
\text { hansénienne traitée } \\
\text { par } \\
\text { polychimiothérapie au } \\
\text { Sénégal. }\end{array}$ & $\begin{array}{l}\text { As lesões orofaciais da lepra não tratada são } \\
\text { conhecidas há muito tempo. Nosso estudo } \\
\text { concentrou-se no estado buco-dental e facial de } \\
97 \text { pacientes com hanseníase submetidos à } \\
\text { poliquimioterapia. }\end{array}$ \\
\hline 14 & $\begin{array}{c}\text { Santos et al. } \\
2007\end{array}$ & $\begin{array}{l}\text { Anais Brasileiro } \\
\text { de Dermatologia }\end{array}$ & $\begin{array}{l}\text { Pesquisa de } \\
\text { Mycobacterium } \\
\text { leprae em biópsias de } \\
\text { mucosa oral por meio } \\
\text { da reação em cadeia } \\
\text { da polimerase }\end{array}$ & $\begin{array}{l}\text { Determinar se o genoma do Mycobacterium } \\
\text { leprae pode ser encontrado pelo teste da PCR em } \\
\text { biópsias com punch da mucosa oral de pacientes } \\
\text { com hanseníase }\end{array}$ \\
\hline 15 & $\begin{array}{l}\text { Tehari et al. } \\
2012\end{array}$ & $\begin{array}{l}\text { Medicina } \\
\text { Oral, } \\
\text { Patologia Oral } \\
\text { y Cirugia } \\
\text { Bucal }\end{array}$ & $\begin{array}{l}\text { Oro-facial } \\
\text { manifestations of } 100 \\
\text { leprosy patients }\end{array}$ & $\begin{array}{l}\text { Verificar a frequência de acometimento oral e } \\
\text { facial em pacientes com diagnóstico de } \\
\text { hanseníase }\end{array}$ \\
\hline
\end{tabular}

Fonte: dados coletados de estudos publicados no período de 1990 a 2018.

Foi realizada leitura de todos os títulos e resumos, respeitando-se os critérios de inclusão e exclusão, selecionando os estudos para análise detalhada.

As palavras-chave mais utilizadas pelos autores foram "saúde bucal e hanseníase", presentes em $61 \%$ dos estudos. Como o foco deste estudo era analisar a produção científica nacional e internacional da odontologia voltado a pacientes com hanseníase, de uma forma ampla, utilizamos as palavras com maior probabilidade de aparecerem nos artigos. Verificamos que $93,4 \%$ dos artigos apresentam os objetivos do estudo de forma clara, ou seja, possibilitam o fácil entendimento do leitor.

De acordo com estudo N04, a integralidade no atendimento ao paciente torna a consulta mais efetiva pois dessa forma o paciente não se torna um mero sistema biológico, mas um ser completo com necessidades físicas, emocionais, psíquicas e biológicas, assim não avaliaremos a boca do paciente, mas o paciente como um todo, procurando ouvir suas necessidades de saúde não verbalizadas ou explícitas. Dessa forma o diagnóstico diferencial a partir da anamnese correta vai ajudar esse paciente a sentir-se valorizado e acolhido.

No estudo N08 ficou evidenciado que pacientes com hanseníase apresentam as condições bucais desfavoráveis, tornando-os pacientes potenciais à doença cárie e doenças periodontais. Esses pacientes necessitam de um atendimento integral devido a diminuição de imunidade da microbiota oral, devido ao tratamento com multidrogas (Dapsona, Clofazimina e Rifampicina) preconizado pela OMS desde 1981, podendo desencadear efeitos adversos na mucosa oral, por isso, o acompanhamento odontológico minimiza esses problemas aumentado assim a qualidade de vida e saúde oral. 
No estudo N10 a autopercepção da pessoa com hanseníase em relação a sua saúde bucal favorece um tratamento precoce diminuindo os agravos que a doença pode trazer para o paciente, possibilitando uma avaliação clínica, acompanhamento continuado do paciente e serve como guia para um planejamento de políticas públicas que favoreça o tratamento odontológico mais efetivo.

No estudo N05 os autores em suas pesquisas relatam que muitos cirurgiões dentistas durante o período de formação relataram que os aspectos da doença hanseníase é abordado de maneira superficial e distante da realidade das práticas odontológicas, o que resulta em uma formação do cirurgião dentista sem uma visão integral do indivíduo e desconhecendo as consequências que a doença traz para seus portadores. Como consequência há dificuldade no diagnóstico precoce de pacientes atendidos nas unidades de saúde básica do SUS ou em consultórios particulares, mantendo esses pacientes como fonte de infecção, sem um diagnóstico e tratamento adequado, mantendo estes pacientes com carga bacilar alta e diminuindo as chances de cura da doença.

Em relação à prática odontológica, apenas 8 artigos ressaltam a importância de um protocolo adequado as necessidades desses pacientes já que o cirurgião dentista muitas vezes desconhece alguns sinais e sintomas da doença e a melhor abordagem na prevenção de lesões que são próprias da hanseníase.

Com base em todos esses dados é necessário conhecer o mecanismo de infecção do Mycobacterium leprae na cavidade oral e suas implicações para o paciente. Segundo Santos et al. (2000) o bacilo pode estar presente na mucosa bucal sem apresentar qualquer alteração morfológica clinicamente visível, o que sugere uma resistência ao surgimento de lesões neste local. Considera-se, portanto, que a invasão da mucosa oral é decorrência da bacilemia pela disseminação e multiplicação bacteriana (SONI, 1992).

Ao contrário das manifestações cutâneas, que são descritas exaustivamente na literatura médica, são poucos os estudos publicados que tratam das manifestações orais na hanseníase, e faltam descrições detalhadas sobre esse assunto nos livros textos padrões. A maioria das referências é antiga, da época em que os pacientes evoluíam ao longo dos anos pela falta de um tratamento eficaz para a doença. $\mathrm{Na}$ literatura recente, e nos artigos encontrados em nossa revisão integrativa, mesmo em plena fase da multidroga-terapia, faltam dados sobre o comprometimento da mucosa oral pela hanseníase e conscientização da importância do tratamento odontológico dos pacientes com hanseníase (ALMEIDA et al., 2011).

Dessa forma, percebe-se uma grande avanço das pesquisas que envolvem a problemática do mal de Hansen, um esforço dos pesquisadores da odontologia em compreender o mecanismo de infecção do Mycobacterium leprae e seu envolvimento com a cavidade oral. Acreditamos que essa nova temática de importância à saúde pública será construída com artigos mais específicos e completos referente aos protocolos de atuação, assim, os profissionais da odontologia compreenderão melhor a patogênese da hanseníase e suas implicações aos pacientes portadores.

\section{CONSIDERAÇÕES FINAIS}

De acordo com as publicações analisadas nesta revisão, há poucos artigos de pesquisas odontológicas referente a hanseníase e protocolos adequados à atenção odontológica. Pelo fato de a Hanseníase ser um problema de saúde pública em nosso país é importante que o cirurgião dentista tenha uma visão integral do atendimento odontológico. Este atendimento inclui o diagnóstico precoce, o encaminhamento do paciente ao tratamento, a identificação e conhecimento de lesões orofaciais características da doença.

Frente a esse fato, sugerimos que os pesquisadores da área de odontologia aumentem as produções bibliográficas para uma melhor compreensão do mecanismo de infecção e as consequências do Mycobacterium leprae em relação a cavidade oral. 
Assim, os artigos derivados das pesquisas e analisados nessa revisão, focalizando as diferentes dimensões da atuação do cirurgião dentista, apresentam vários cenários, mesmo que de forma tímida, estão contribuindo para o desenvolvimento do conhecimento e atenção integral e humanizada aos pacientes que são ou foram portadores de Hanseníase.

\section{REFERÊNCIAS}

1. ALMEIDA JR. Autopercepção de pessoas acometidas pela hanseníase sobre sua saúde bucal e necessidade de tratamento. Ciênc. saúde coletiva, Rio de Janeiro, v. 18, n. 3, p. 817-826, Mar. 2013.

2. ALMEIDA J, ALENCAR C, BARBOSA J et al. Contribuição do cirurgião-dentista no controle da hanseníase. Cad. Saúde Colet., 2011, Rio de Janeiro, 19 (3): 271-7272.

3. ALMEIDA J, ALENCAR C, BARBOSA J et al. Oral health conditions in leprosy cases in hyperendemic area of the Brazilian Amazon. Rev. Inst. Med. trop. S. Paulo, São Paulo, v. 59, e 50, 2017.

4. ALMEIDA J, ALENCAR C, BARBOSA J et al. Contribuição do cirurgião-dentista no controle da hanseníase. Caderno de Saúde Coletiva. 19, 3, 271-277, 2011.

5. ALMEIDA M, RODRIGUES R, FUREGATO A et al. A pós-graduação na Escola de enfermagem de Ribeirão Preto - USP: evolução histórica e sua contribuição para o desenvolvimento da enfermagem. Rev. Latino-am. Enfermagem 2002 maio/junho; 10(3): 276-87.

6. BRASIL. Ministério da Saúde. Secretaria de Vigilância em Saúde. Departamento de Vigilância Epidemiológica. Programa Nacional de Controle da Hanseníase. Vigilância em Saúde: situação epidemiológica da hanseníase no Brasil. Brasília: Núcleo de Comunicação, 2013.

7. BURNS N, GROVE SK. The practice of nursing research: conduct, critique and utilization. 4 ed. Philadelphia: W B Saunders; 2001.

8. CORTELA DC, IGNOTI E. Conhecimento e experiências do cirurgião-dentista sobre hanseníase em Cáceres, MT, Brasil. Revista Odonto ciências. PUC- RS. 23(3): 243-250, jul.-set. 2008.

9. CORTELA DC, IGNOTTI E. Lesões visíveis na hanseníase: o papel do cirurgião-dentista na suspeita de casos novos. Rev. bras. epidemiol., São Paulo, v. 11, n. 4, p. 619-632, Dec. 2008.

10. DAVE B, BEDI RI. 2013. Leprosy and its dental management guidelines. International Dental Journal , 63(2): 65-71, 2013 Apr.

11. DIALLO B, COURDERT J, DENIS G et al. Evaluation de l'état orofacial et dentaire d'une population hansénienne traitée par polychimiothérapie au Sénégal. Acta leprologica 8(1):11-5 - February 1992.

12. FENG Y, YANG Y, TIAN L et al. Dental health and treatment needs in people with leprosy in China. Leprosy Review, 2014, Dec;85(4):311-21

13. FILGUEIRA A AI. Saúde bucal em indivíduos com hanseníase no município de Sobral, Ceará. Epidemiol. Serv. Saúde, Brasília, v. 23, n. 1, p. 155-164, Mar. 2014.

14. FUCCI C, NERY P, OLIVEIRA J et al. Oral lesion in leprosy. Indian Journal of Dermatology, Venereology and Leprology, v. 69, p.3815, 2003.

15. GANONG LH. Integrative reviews of nursing research. Res Nurs Health, 1987 February; 10(1):1-11.

16. MARTINS C, CARVALHO C, MOREIRA J et al. Estudo restrospectivo de dez anos em endoscopia das cavidades nasais de pacientes com hanseníase. Revista Brasileira de Otorrinolaringologia, v. 71, n. 5, p. 609-16, set./out., 2005.

17. MARTINS R, CARLONI M, GARBIN C et al. Dentists' knowledge and experience regarding leprosy in an endemic area in Brazil. Rev. Inst. Med. trop. S. Paulo, São Paulo, v. 58, e 76, 2016 Nov 03.

18. NEVILLE BW, DAMM DD. Patologia Oral e Maxilofacial. 3a edição. Rio de Janeiro: Elsevier, 2009.

19. Núñez Martí,. Calidad odontológica en pacientes con Hansen. Revista de leprologia Fontilles. Espanha, 21(5): 511-518, mayo 2000.

20. OSUGUE SS, OSUGUE YS. Rotinas de diagnóstico e tratamento das doenças infecciosas e parasitárias. São Paulo: Editora Atheneu, 2005.

21. PONTES B, ALMEIDA G, AOBA E et al. Detecção do DNA de Mycobacterium Leprae em secreção nasal. Revista Brasileira de Enfermagem, v. 61(esp), p. 734-7, 2008.

22. RUSSO M, CORRÊA T, MARTINS D et al. Aspectos da doença de Hansen relevantes para o cirurgião-dentista: revisão da literatura. Revista Odonto Ciência - Fac. Odonto/PUCRS, v. 20, n. 48, abr./jun. 2005

23. SANTOS G, MARCUCCI G, GUIMARÃES J et al. Pesquisa de Mycobacterium leprae em biópsias de mucosa oral por meio da reação em cadeia da polimerase. Anais Brasileiro de Dermatologia. v.82, p. 245-9, 2007.

24. SANTOS G, MARCUCCI G, JÚNIOR G et al. Aspectos estomatológicos das lesões específicas e não-específicas em pacientes portadores da moléstia de Hansen. Pesq. Odontol. Bras.,v.14, n.3, p.268-272, 2000.

25. SANTOS, GG. Aspectos estomatológicos das lesões específicas e não-específicas em pacientes portadores da moléstia de Hansen. Pesqui. Odontol. Bras., São Paulo, v. 14, n. 3, p. 268-272, Sept. 2000.

26. SANTOS, GG. Pesquisa de Mycobacterium leprae em biópsias de mucosa oral por meio da reação em cadeia da polimerase. An. Bras. Dermatol. Rio de Janeiro, v. 82, n. 3, p. 245-249, June 2007.

27. SILVEIRA CS, ZAGO MF. Pesquisa brasileira em enfermagem oncológica: uma revisão integrativa. Rev Latinoam Enfermagem 2006 julho-agosto; 14(4):614-9.

28. SONI, NK. Leprosy of the tongue. Indian J Lepr, v.64, n.3, p.325-30, 1992.

29. TEHARI J, MAHIN B, HAMED M et al. Oro-facial manifestations of 100 leprosy patients. Medicina Oral, Patologia Oral y Cirugia Bucal, 2012 Sep; 17(5): e728-e732

30. WHO. World Health Organization - Leprosy: Global Situation, 2014. 